\title{
Spatial market integration in the era of high food prices. A case of surplus and deficit maize markets in Kenya
}

\section{Raphael Gitau ${ }^{a}$ and Ferdi Meyerb}

\begin{abstract}
Kenya, like most countries in the East Africa Region has continued to be beleaguered by unabated high and volatile food prices. The government in an effort to counter these challenges has instituted various policies aimed at reversing the situation. This paper is aimed at examining spatial maize market integration in the presence of non-constant transaction costs and policies implemented. Findings indicate that market pairs close to each other were integrated, had a lower transaction costs and the price differential across markets were quickly corrected compared to markets further apart. Evaluation of the effects of policies on market integration shows the implementation of policies resulted in market distortion. The price difference between surplus and deficit markets were not corrected hence equilibrium was not achieved. When markets are poorly integrated, the price mechanism does not work and price signals cannot be transmitted thus allowing for efficient exchange of food products across spatial markets.

To reduce transaction costs in the maize sector, the government should improve the road infrastructure connecting production areas with the markets and between markets. Harmonization of the local government levies imposed on maize traversing different local municipalities will help reduce transaction costs. On the fertilizer subsidy, the government needs to collaborate with the private sector as it has a wide distribution network countrywide. This will ensure accessibility of the fertilizer by farmers in remote areas. Market forces should guide participation of the marketing board in the maize market. The board should not succumb to political pressure by purchasing maize at a higher price than the market prices.
\end{abstract}

Key Words: Market integration; policy intervention; high food prices;

JEL Classifications: C32, D4, D5, Q18, R32

\footnotetext{
${ }^{a}$ Department of Agricultural Economics, Rural Development and Extension, University of Pretoria, South Africa. Tegemeo Institute of Agricultural Policy and Development-Egerton University. Corresponding author grkanyingi02@gmail.com

${ }^{\mathrm{b}}$ Bureau of Food and Agricultural Policy (BFAP), Department of Agricultural Economics, Rural Development and Extension, University of Pretoria, South Africa.
} 


\section{Introduction}

The global food and energy crises experienced during 2008/09 ignited interest amongst policy makers and policy analysts. This followed the threat to political instability and the social impact experienced especially across many developing economies. An increase in incidents of hunger, malnutrition, food insecure population, emergency food aid and food riots were some of the manifestation of price hikes. To counter these crises, most governments instituted emergency measures such as, food aid, input subsidies, and policy instruments aimed at stabilizing domestic food prices.

Despite the decline in global food and energy prices, many countries in the East and Southern Africa (ESA) region have continued to experience volatile and high food prices compared to the world prices since 2008 (Minot, 2014). Domestic factors and to some extent regional factors play a crucial role in the determination of staple food prices. These factors are market specific such as demand and supply shock, macroeconomic specific such as capital flow and policy shocks among other factors. In addition, the region is self-sufficient or almost self-sufficient in staple foods such as maize. Hence, international staple markets have little or no effects on domestic markets. All these factors combined may elucidate why the region has continued to face volatile and high food prices (Karugia et. al., 2010: Nzuma et. al. 2013; Minot 2014).

To even out commodity prices, households are willing to forego a portion of their returns. From a risk perspective, a large proportion of the population which spends a large share of their budgetary expenditure on foodstuffs will be disenfranchised by high and volatile food prices (Barret, 1996; Finkelshtain and Chalfant 1997;Bellemare et.al, 2013;Minot, 2014). Stable food prices ensure welfare gain in the society. Most governments in the region have been keen on safeguarding the rural and urban poor population against price hikes by stabilizing food prices. The strategy applied to stabilize food prices by most governments has been the use of marketing and trade policy instruments. The success of policies are dependent on the government ability to implement the specific policies. Most of the policies implemented to stabilize food prices have not achieved their desired effects. Chapoto and Sitko (2014) noted that most policies implemented in the region were, erratic, highly discretionary, sudden and inconsistent. As a result, they did not achieve their intended goal. Findings from studies indicates over the past decade markets with more government interventions observed higher price volatility (Chapoto \& Jayne 2009; Jayne 2012).

A strong price mechanism contributes to scarce resource allocation and economic growth. When markets are well-integrated, they have an impact on price discovery and market operations and are significant in addressing high and volatile food prices. These markets ensure 
efficient movement of trade flow and the exchange of food products across surplus and deficit regions. They also allow for the designing of suitable market policies. Most studies done with respect to food markets have mainly focused on the integration between the world and major domestic markets. Little or no focus has been given to the link between domestic staple food markets, despite little or no price transmission from the world to domestic markets. The lack of price transmission or low price transmission between the two markets is attributed to insulation of domestic markets by policy (Benson et. al 2008; Cudjoe et. al Diao 2010; Minot 2011;Baltzer, 2013). Therefore, domestic markets and in some case the regional markets play a significant role in the movement of staple foods. Focussing on improving these markets will facilitate the smooth flow of food from surplus to deficit areas and stabilize prices.

In Kenya, there has been limited comprehensive work done on the extent and degree of domestic spatial grain market integration especially between surplus and deficit regions. The studies undertaken used cointegration and causality test and did not account for transaction costs (Gbegbelegbe and de Groote 2012; Nzuma, 2013; Ngare et. al. 2013). To the best of our knowledge there are no studies done in Kenya that have included transaction costs and effects of policy shocks on market integration. This study is an attempt to address this gap through empirically investigating the spatial market linkage between surplus and deficit markets in the presence of transaction costs and policy interventions. The study also incorporates more markets than the previous studies undertaken.

The rest of the paper is organized as follows, Section two discusses the conceptual framework, econometric framework and data used are presented in section three. Section four describes the maize sector in Kenya while the results of the study are presented in section five. Section six concludes.

\section{Conceptual framework}

Integration and efficiency are two distinctive concepts. The concept of integration is restricted to the flow-based notion of tradability, whereas efficiency is a price-based concept that relates to the satisfaction of equilibrium conditions (Barret, 2001). Market integration is defined as the transfer of walrasian excess demand from one market to another. This may be either in the form of physical flow of commodity or the transmission of price shocks or both. Although the physical flow of goods between two markets is sufficient, it not necessary to demonstrate tradability.

At the core of various spatial market integration studies is the market equilibrium theory named after the authors, Enke (1951), Samuelson (1952) and Takayama and Judge (1971). The theory 
is commonly referred to as ESTJ market equilibrium theory. The theory refers to the price dispersion between two locations for an identical good bonded from above by the cost of arbitrage between the two markets with no trade volume restriction and bounded from below when trade volumes reaches a ceiling (Barret,2001). This concept infers several equilibria systems defined by prevailing arbitrage conditions and matching tradability arrangements. The model evaluates interconnection between markets within the concept of tradability, market equilibrium and efficiency. The ESTJ market equilibrium theory underpins the concept of efficiency in spatial market integration. The theory advocate for use of price, transaction costs, trade volumes and trade quotas in the analysis of market integration. A generalized form of ESTJ theory maybe summarized as follows

$$
\begin{array}{cl}
p_{t}^{b}<p_{t}^{a}+\tau_{t}^{a b} & \text { if } q_{t}^{a b}=0 \\
p_{t}^{b}=p_{t}^{a}+\tau_{t}^{a b} & \text { if } q_{t}^{a b} \in\left(0, q_{t}^{z}\right) \\
p_{t}^{b}>p_{t}^{a}+\tau_{t}^{a b} & \text { if } q_{t}^{a b}=q_{t}^{z}
\end{array}
$$

Where $p_{t}^{b}$ and $p_{t}^{a}$ are the prices in market $\mathrm{b}$ and a in time t respectively. $\tau_{t}^{a b}$ is the transfer cost from market a to $\mathrm{b}$ at time $\mathrm{t}$ while $q_{t}^{a b}$ represent the physical flow of trade between market $\mathrm{a}$ and $\mathrm{b}$ in time t. $q_{t}^{Z}$ represents the maximum trade allowed between this two market. The spatial price difference between the two markets in equation 2.1 is less than the transfer costs. No arbitrage opportunities between the two markets exists for traders to engage in trade. The two markets are spatially efficient if no trade occurs and inefficient if trade occurs. The spatial price difference in equation 2.2 will equal transfer costs. This is consistent with spatial market efficiency irrespective of trade occurring. When trade occurs we expect that $p_{t}^{b}$ and $p_{t}^{a}$ will differ from autarky price thus demand and supply shocks will be moved between the markets. Competitive equilibrium also holds under these conditions (Barret and Li, 2002; Negassa and Meyers, 2007). The spatial price difference in equation 2.3 is greater than the transfer costs. There are unexploited arbitrage opportunities hence these markets are spatially inefficient irrespective of the occurrence of trade. These markets are characterized by imperfect competitive equilibrium. Several factors may lead to this situation such as, traded volume quotas, non-competitive market practises and government policies.

\section{Econometric framework}

The threshold auto regression model (TAR) was introduced by Tong and Lim (1980) and later discussed exhaustively by Tong (1990). The model assumes a regime that is determined by a variable $c_{t}$ relative to a threshold value. In spatial market integration, transaction costs are the threshold effects that plays a role in the mechanism leading to spatial equilibrium across the 
markets if the price spread differential is above or below transaction costs. The TAR model is a statistical model that is consistent with spatial efficiency but allows for deviation from the efficiency condition as well as a dynamic adjustment over time. The TAR model takes the following form

$$
\begin{array}{ll}
\Delta A_{t}=\lambda+\sum_{k=1}^{k} \gamma_{k} \Delta A_{t-k}+\varepsilon_{t} & \text { if } A_{t} \leq \tau_{t} \\
\Delta\left(A_{t}-\tau_{t}\right)=\lambda\left(A_{t-1}-\tau_{t-1}\right)+\sum_{k=1}^{k} \gamma_{k} \Delta\left(A_{t-1}-\tau_{t-1}\right)+\varepsilon_{t} & \text { if } \mathrm{A}_{t}>\tau_{t} \\
\Delta\left(A_{t}+\tau_{t}\right)=\lambda\left(A_{t-1}+\tau_{t-1}\right)+\sum_{k=1}^{k} \gamma_{k} \Delta\left(A_{t-1}+\tau_{t-1}\right)+\varepsilon_{t} & \text { if } \mathrm{A}_{t}<\tau_{t}
\end{array}
$$

$A_{t}$ represents the price spread between two spatial markets $\mathrm{A}$ and $\mathrm{B}\left(P^{A}-P^{B}\right)$ in the period t. $\Delta$ is the first difference operator $\left(\Delta A_{t}=A_{t}-A_{t-1}\right)$. $\lambda$ represent the speed of adjustment. $\tau_{t}$ is the transfer costs and represent the threshold variable which defines a boundary for when the price spread is too small or too larger to encourage trade between the two markets. Equation 3.1 represents regime one. The price differential is sufficiently small, hence no incentive for trade. There is no link between the prices in the two markets. Regime two is represented by equation 3.2. Under this regime, the price spread is positive and larger enough in absolute value to encourage trade from market B to A. This result in the adjustment of the price spread back to the transfer cost boundary. Under regime three (3.3), the price spread is negative and large enough in absolute value to encourage trade reversal from market $\mathrm{A}$ to $\mathrm{B}$. This leads to the price spread adjusting back to the transfer cost boundary.

Arbitrage conditions, the price spread and market integration can be potentially influenced by non-constant transaction costs. The TAR models and its extension are capable of capturing this non-linearity in prices. The models are capable of incorporating realistic observable patterns in the market that results in equilibrium across spatial markets. This are details missed by previous methodologies. Despite these advantages, TAR models have high computational costs associated with the estimation procedures. This is true when we have more than two regimes as a multi-parametric grid-based exploration over an entirely possible value of all threshold parameters is required for a global minimum of a least square criterion ( $\mathrm{Li}$ and Ling,2012: Chang et al. 2015).

The TAR model has two weaknesses. The first weakness is the standard assumption in literature of a time invariant transaction costs (Goodwin and Piggot, 2001; Sarno et. al, 2004). To deal with constant transaction, studies have introduced a time trend to the equation (Van Campenhout, 2007; Amikuzono, 2012). The second weakness is with respect to the thresholds of the parameters whose asymptotic scattering of the threshold parameter is neither normal nor nuisance parameter free. This makes it impossible to obtain standard errors and confidence 
intervals as shown by Chan (1993). This argument was later disputed by Hansen (1996), Li and Ling (2012). These researchers developed a mathematical methodology to mimic the limiting distribution of the estimated threshold through an associated compound poisson process. Based on the mathematical results, one would then construct a confidence interval, thereby solving the problem highlighted by Chan (1993).

For our study, the price differential denoted by $R$, across spatial markets comparing a deficit markets (net consumer), signified by $d$ and a surplus market signified by $s$, is expressed as follows $d^{d s}=P_{t}^{d}-P_{t}^{s}$. Therefore, a TAR model evaluates the reaction of the price difference at time $t$ to the price difference at time $t-1$. A TAR model ensues when a size of lagged price differential or equilibrium shock culminates to a different degree in change which occurs in a regime fashion. The adjustment parameter varies according to whether the shock introduced into the system is bigger or smaller than a threshold value. This is represented by the effects that $d_{t-1}^{d s}$ has on $d_{t}^{d s}$ which is expressed as follows

$\Delta d_{t}^{d s}=\rho d_{t-1}^{d s}+\varepsilon_{t}$

Where $\Delta d_{t}^{d s}=d_{t}^{d s}-d_{t-1}^{d s}$ represent the change in the price difference between period $t-$ 1 and $t$.The speed of adjustment is represented by $\rho$. This measure the rate at which price difference in $t-1$ is corrected to achieve equilibrium prices between $d$ and $s$ markets. The residual term is assumed to be $\varepsilon \sim N\left(0, \sigma^{2}\right)$. Transaction costs are expected to influence price adjustment and they vary over time. Hence, equation (3.4) is not appropriate as it does not account for these changes. To correct for this we allow price adjustment to vary with respect to the lagged price margin $d_{t-1}^{d s}$ either being above or below a threshold $\tau^{d s}$ which is represented by the transaction cost. The new model is specified as follows,

$\Delta d_{t}^{d s}=\left(\begin{array}{c}\rho^{\text {out }} d_{t-1}^{d s}+\varepsilon_{t}, \text { if } d_{t-1}^{d s}>\tau^{d s} \\ \rho^{\text {in }} d_{t-1}^{d s}+\varepsilon_{t}, \text { if }-\tau^{d s} \leq d_{t-1}^{d s} \leq \tau^{d s} \\ \rho^{\text {out }} d_{t-1}^{d s}+\varepsilon_{t}, \text { if } d_{t-1}^{d s}<-\tau\end{array}\right)$

$\rho^{\text {in }}$ is the adjustment parameter when the price margin is below the threshold $\tau^{d s}$ whereas $\rho^{\text {out }}$ represents the adjustment parameter when the absolute value of the price margin surpasses $\tau^{d s}$. It is generally assumed that the adjustment within the band formed by the threshold values is a purely stochastic process thus no adjustment within the band $\left(\rho^{\text {in }}=0\right)$. The lower $\left(-\tau^{d s}\right)$ and upper $\left(\tau^{d s}\right)$ threshold values demarcate trade into three regimes. Profitable arbitrage opportunities exist in the two outer regimes signified by $d_{t-1}^{d s}<-\tau^{d s}$ or when $d_{t-1}^{d s}>\tau^{d s}$ thus the need for full exploitation by traders. Goodwin and Piggot (2001) and 
Sarno et al (2004) noted that the standard assumption in literature was that transaction cost was constant as inferred in the TAR model. Model (3.5) assumes a constant threshold value. Transaction costs in Kenya may vary according to season, the quality of the road, distance the product is being shipped, the number of municipalities traversed, among other factors. Model (3.5) is extended to include a time trend $t$ in the adjustment and threshold parameters as per Van Campehout (2007). The new model is specified as follows,

$\Delta d_{t}^{d s}=\left(\begin{array}{c}\rho^{\text {out }} d_{t-1}^{d s}+\rho_{t}^{i} d_{t-1}^{d s}+\varepsilon_{t}, \text { if } d_{t-1}^{d s}>\tau_{t}^{d s} \\ \rho^{\text {in }} d_{t-1}^{d s}+\rho_{t}^{\prime} d_{t-1}^{d s}+\varepsilon_{t}, \text { if }-\tau_{t}^{d s} \leq d_{t-1}^{d s} \leq \tau_{t}^{d s} \\ \rho^{\text {out }} d_{t-1}^{d s}+\rho_{t}^{\prime} d_{t-1}^{d s}+\varepsilon_{t}, \text { if } d_{t-1}^{d s}<-\tau_{t}^{d s}\end{array}\right)$

$\rho_{t}^{\prime}$ and $\tau_{t}^{d s}$ represent the speed of the price adjustment parameter and threshold variables respectively which vary with time. The range from 0 to $T$ is representative of time $t$. When $t=0$ then the threshold will be $\tau_{0}^{d s}$ and at time $T$ it will be $\tau_{T}^{d s}$. Similar to model (3.5), model (3.6) has three regimes and assumes no adjustments within the band. With the assumptions of no adjustment within the band model, (3.5) and (3.6) are reduced into model (3.7) and (3.6) respectively which are estimated via a grid search.

$$
\begin{aligned}
& \Delta d_{t}^{d s}=\left(\begin{array}{c}
\rho^{\text {out }} d_{t-1}^{d s}+\varepsilon_{t}, \text { if } d_{t-1}^{d s}>\tau^{d s} \\
\varepsilon_{t} \quad \text { if }-\tau^{d s} \leq d_{t-1}^{d s} \leq \tau^{d s} \\
\rho^{\text {out }} d_{t-1}^{d s}+\varepsilon_{t}, \text { if } d_{t-1}^{d s}<-\tau
\end{array}\right) \\
& \Delta d_{t}^{d s}=\left(\begin{array}{rr}
\rho^{o u t} d_{t-1}^{d s}+\rho_{t}^{\prime} d_{t-1}^{d s}+\varepsilon_{t}, \text { if } d_{t-1}^{d s}>\tau_{t}^{d s} \\
\varepsilon_{t}, & \text { if }-\tau_{t}^{d s} \leq \tau_{t}^{d s} \\
\rho^{o u t} d_{t-1}^{d s}+\rho_{t}^{\prime} d_{t-1}^{d s}+\varepsilon_{t}, \text { if } d_{t-1}^{d s}<-\tau_{t}^{d s}
\end{array}\right)
\end{aligned}
$$

\section{Maize sector in Kenya}

In Kenya, maize is the main staple and its plays a critical role both nationally and at the household level. Nationally, maize plays a significant role in food security, feed industry and it is a central crop in agriculture. At the household level, maize is both source of food and income. Over the years, maize has been equated to food security a fact that policy-makers in Kenya have laid emphasis on in the past food policy documents. In the computation of food inflation, maize carries a $13 \%$ weight. It accounted for $25 \%$ of the total caloric intake for both urban and rural households in 2013 and 2015 (Nzuma, 2013; OECD- FAO, 2016). 
In the feed industry, maize forms the key ingredient constituting over $80 \%$ of feed rations. In the agricultural sector, the crop is central as it constitutes of $56 \%, 51 \%$ and $40 \%$ of the cultivated land, all staple grown and total crops grown respectively. Majority of the small-scale farmers (98\%) cultivate maize and combined with medium-scale farmers account for $75 \%$ of the crop produced nationally.

At the household level, maize has continued to play a critical role in the welfare of households. Over the past decade, the contribution of maize to the gross value of crop income increased from $30 \%$ to $47 \%$ while its contribution to the overall income declined from $11 \%$ to $9 \%$ (Jayne et al. 2001; Suri et al. 2008; Kirimi et al. 2011; Njagi et al. 2015).Kenya's maize per capita consumption is the highest in the Eastern African region. It's estimated at 103 kilograms (Abate et al. 2015). Consumption studies shows poor households mainly consume maize. The share of maize and maize products constituted $37 \%$ of the total staple food expenditure among $20 \%$ of urban poorest households while $20 \%$ of the urban wealthiest expenditure was only $1 \%$ (Kamau et al. 2011). Although the importance of maize is declining, especially amongst the wealthy households, it still plays an important role to both the urban and rural poor. Hence, the need to stabilize food prices as this would have a positive welfare effect on these households. According to the Ministry of Agriculture, Livestock and Fisheries (MOALF), maize production is based on the geographical stratification and seasonality in Kenya. This is the main determinant of the disparity in maize production and supply. The Rift valley region forms the major surplus region accounting for $51 \%$ of national production and over $60 \%$ of the national marketed maize surplus. The region has one main maize harvest season that starts from October through to December. Trans Nzoia and Usain Gishu county produces the bulk of maize in the region. The surplus markets analysed in this study are located in these two counties. High population density and net ${ }^{1}$ maize consumers characterize the deficit maize producing regions. These regions have two maize harvest seasons. The main season is in February and March while the short season starts from July to September. The deficit regions include, Western, Nyanza, Central, Eastern and North Eastern regions. In addition, the three major cities of Nairobi, Mombasa and Kisumu also forms part of these deficit markets.

Over the past decade, the annual national maize requirement was about 3.5 million metric tons. During the same period, Kenya produced an average of 3.2 million metric tons annually depending on the weather and marketing conditions. The deficit was met through imports from

\footnotetext{
${ }^{1}$ Households that consume more maize than they produce and have to depend on the market to bridge the deficit.
} 
the region mostly Uganda and Tanzania and intermittently from overseas during drought seasons.

In Kenya, the maize value chain is made up input suppliers, farmers, market players, processors and post process players. There is competition across the different players. Along the maize value chain, the retail price transmission is asymmetrical supporting the hypothesis of sticky prices. Food prices shows a great response to rising prices than falling prices as observed by Ngare et al. (2013). The authors noted that market pairs that are further apart have a higher speed of price response compared to market pairs close to each other.The maize sector is plagued by high transportation costs due to the poor road network connecting production area with the market and roads connecting surplus and deficit markets. Out of 161,451 kilometres of the public road network in Kenya, $94 \%$ are unpaved ${ }^{2}$. The road board has classified $59 \%$ of the unpaved roads as poor roads (Kenya Roads Board 2015). Due to the poor state of the roads in Kenya, transport costs accounts for $64 \%$ of the marketing costs (World Bank 2009). In addition, maize moving from surplus to deficit region is levied multiple local taxes for traversing different local government municipalities.

After liberalization in the late $90 \mathrm{~s}$, the maize sector had little or no policy intervention from the government. Market forces determined maize prices. There was an increase in the private sector participation and competition along the maize value chain. In addition, low maize prices were observed during this period. The National Cereal and produce Board (NCPB) a state owned marketing board was restructured and its non-core functions of input sales commercialized. The main core-function of the board was the management of the strategic grain reserves. In addition, the board would intermittently participate in the market to stabilize prices if it was required. To maintain the strategic grain reserve $\mathrm{NCPB}$ was expected to purchase maize from the market at the prevailing market prices.

Following the high world food crises in 2007/08 and subsequent price hikes in the domestic markets. The Kenya government implemented various policies aimed at stabilizing food prices. The first policy implemented was the fertilizer subsidy scheme that started in November 2008. The goal of the subsidy program was to stabilize fertilizer prices that recorded the highest prices in the country history in 2008 . The program was also aimed at stimulating maize production and reducing consumer prices. Since the program inception, the proportion of subsidized fertilizer imported has been $20 \%$ of the total national fertilizer requirements estimated at

\footnotetext{
${ }^{2}$ Unpaved road is a dirt road made of native material of the land surface through which it passes. The highway engineers refers to it as subgrade material. Improved forms of unpaved road includes gravel, laterite and murram.
} 
540,000 metric tons. Distribution of the subsidized fertilizer disadvantages small-scale farmers in remote areas as most NCPB depots are located in major towns (Opiyo et al. 2015). Another policy implemented, was the participation of NCPB in the market to stabilize maize prices. Pressure from politicians and large-scale growers resulted in NCPB purchasing maize at a higher price than the prevailing market prices. This has resulted in speculative behaviour by large -scale producers as they hoard maize awaiting the announcement of higher prices by the board. Another policy implemented is the zero rating of import duty on maize imported from outside region. During drought periods in the region, the country import maize from overseas that attracts 50\% import duty. Imported maize usually lower the local prices that are usually high during this period. Although not related to price stabilization, import ban of Genetically Modified Organism (GMO) foodstuffs was another policy implemented. On November 2012, Kenya banned importation of GMO foodstuffs. Although the ban was motivated by health issues, it had an impact on maize prices. As discussed earlier, during drought periods in the region the country turns overseas to import maize. With the ban in effect, the country is forced to source maize from countries that produce GMO free maize and by-pass cheaper maize from countries such as South Africa.

To evaluate effects of policy on market integration we divide the policy implemented into two regimes. The first regime (Jan-2000-Dec-2007) was the liberalized era. The regime was characterized by minimal or no policy intervention, private sector participation, competition and low maize prices. Regime two (Jan-2008-Dec-2016) follows the world high food crises and subsequent domestic food price hikes. It was characterised by government participation into the market to stabilize food prices through implementation of various policies as described above.

\section{Results and discussions}

Data used is from nine markets across Kenya. Two of the markets (Kitale and Eldoret) are located in the major maize surplus region while the other seven markets are net consumers located in deficit regions. Time series data of monthly real ${ }^{3}$ maize prices from January 2000 to December 2016 is used. The descriptive statistics are summarized in Table 5.1. As expected, deficit markets real prices were higher than prices in the surplus region. Garissa market recorded the highest prices followed by Kisii while Mombasa had the least across the deficit markets. Garissa markets usually rely on maize from Nairobi coming from the surplus region

\footnotetext{
${ }^{3}$ The real maize prices are based on deflating the nominal monthly prices using the CPI (Base year Feb, 2009)
} 
especially during the main season (October through December) and during the February-March harvest seasons from the upper Eastern region (mainly Meru and Isiolo). Mombasa market receives maize from within the coastal region, In addition, maize is also received from Nairobi and in some cases from Tanzania through Lunga Lunga and Taveta border points.

Table 5.1: Real maize prices across the markets

\begin{tabular}{lccccc}
\hline Markets & Observations & Mean & Minimum & Maximum & Std. Dev. \\
\hline Eldoret & 204 & 1828 & 918 & 3411 & 477 \\
Garissa & 170 & 2805 & 1170 & 4020 & 727 \\
Kisumu & 204 & 2176 & 1316 & 3875 & 489 \\
Kisii & 153 & 2214 & 1285 & 4015 & 506 \\
Kitale & 115 & 1731 & 829 & 3269 & 518 \\
Machakos & 161 & 2145 & 1099 & 3367 & 505 \\
Mombasa & 204 & 2018 & 1115 & 3573 & 453 \\
Nairobi & 204 & 2106 & 1293 & 3439 & 453 \\
Nakuru & 204 & 1896 & 925 & 3277 & 493 \\
\hline
\end{tabular}

The real maize prices across the markets indicate volatility in the period under review with the highest volatility recorded in 2009 and 2011 (Figure 5.1). The high volatility may-be explained by the drought experienced in 2009 and 2011 when Kenya imported maize from overseas.

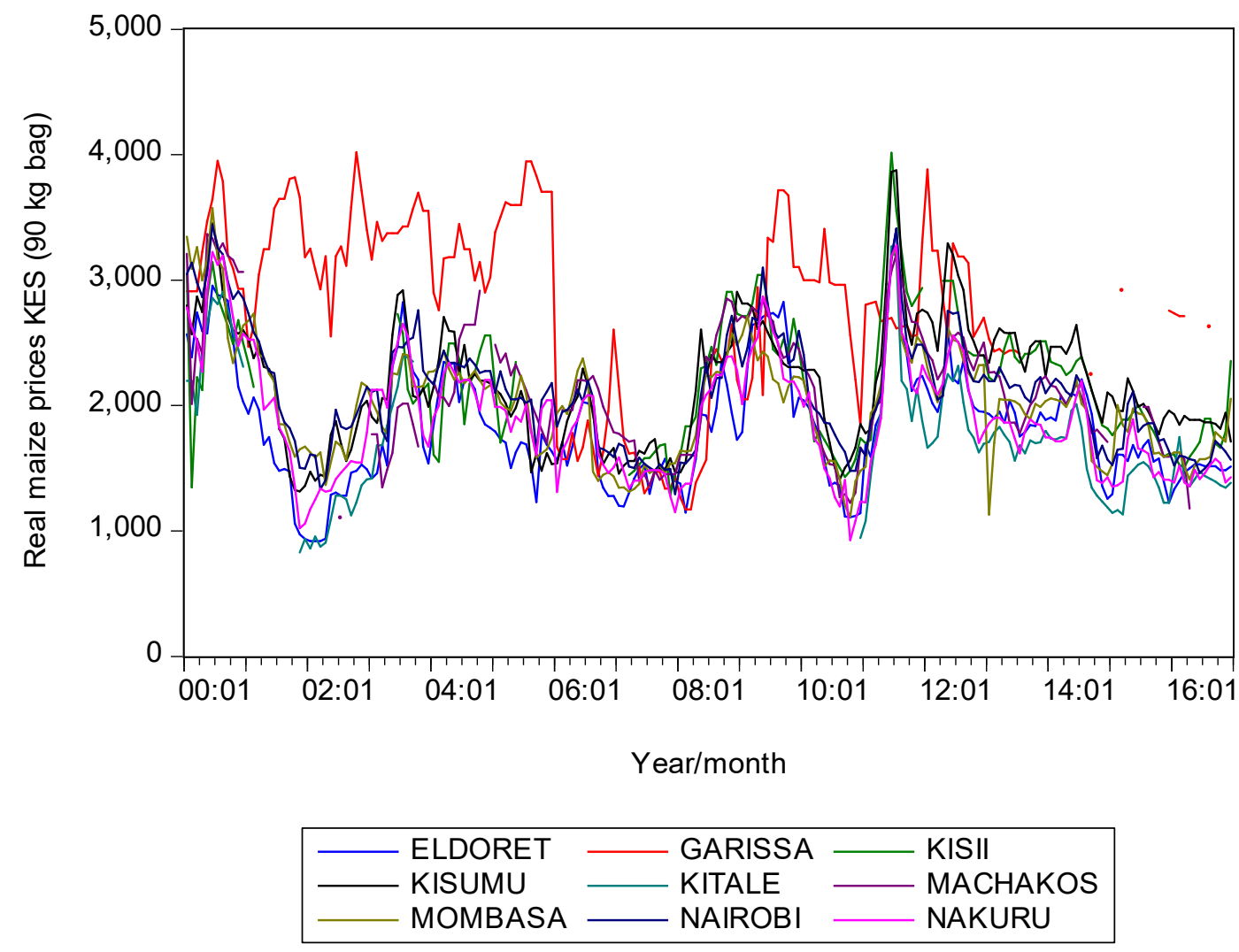

Figure 5.1: Real maize prices across the deficit and surplus markets in Kenya 
The disparity in maize production and supply in Kenya is determined by geographical stratification and seasonality. To evaluate maize price volatility, we compare the lean periods against harvest seasons across the surplus and deficit regions. The unconditional price volatility is computed by dividing standard deviation and mean. Price volatility for the various markets are summarized on Figure 5.2. As expected, the lean periods exhibit higher price volatility compared to harvest periods.

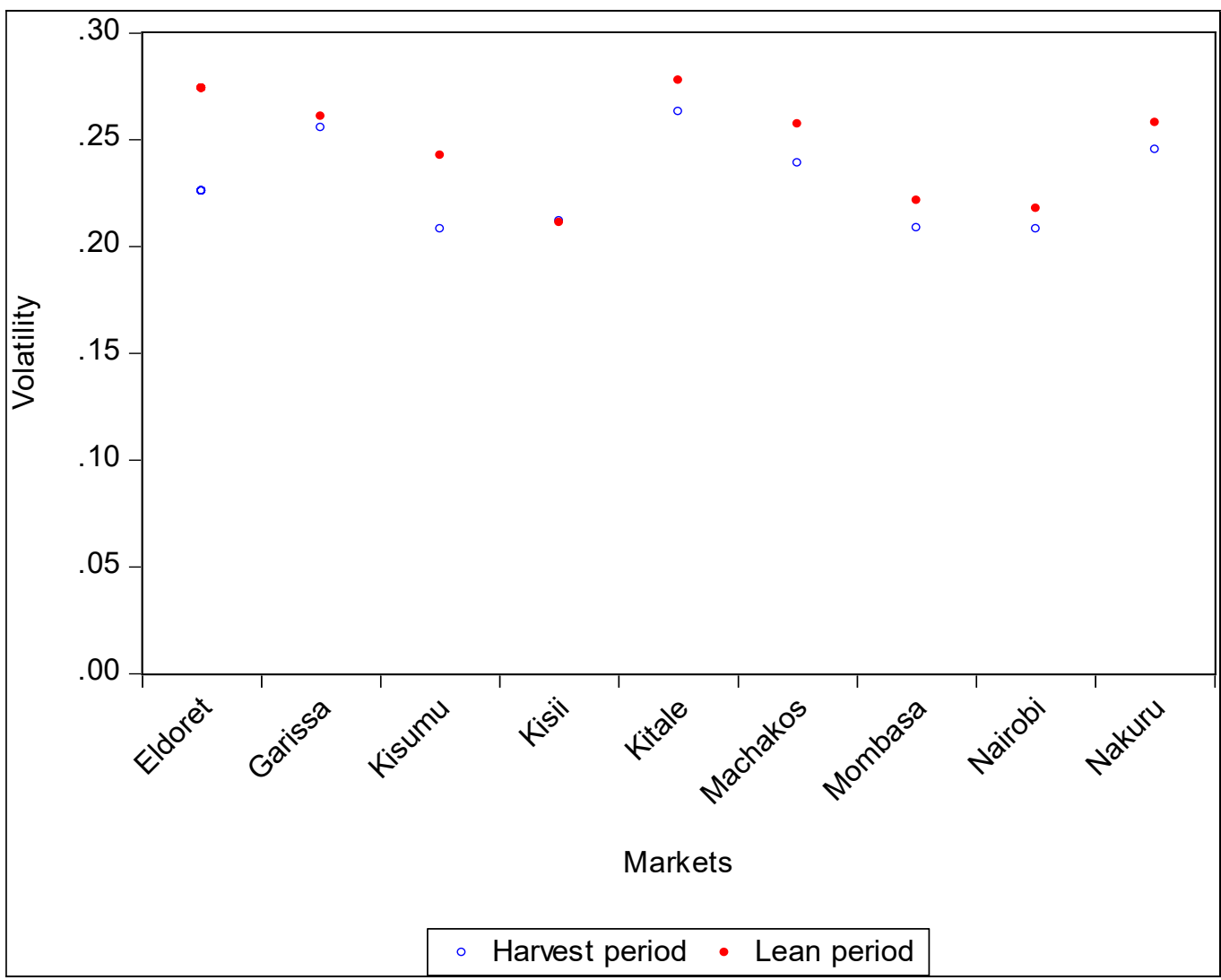

Figure 5.2: Price volatility during harvest and lean period across the various markets

Examining the graph in Figure 5.1 visually shows the volatility of level prices hence the series is not stationary. In addition, the volatility of the level price series is unlikely to go to zero thus we include an intercept. The series does not appear to exhibit a persistent trending behaviour. We exclude a deterministic trend in the unit root and Johansen's cointegration tests (Johansen and Juselius, 1990; Johansen, 1991).

Following the traditional practice of time series analysis, we first tested if prices were stationary. The tests used are the Augmented Dickey Fuller (ADF) and Phillip-Peron (PP) unit root tests. The ADF is an adjustment test that accounts for the possible serial correlation in the error term by adding the lagged difference term. The PP test uses a non-parametric statistical 
method to take care of serial correlation without the addition of the lagged difference term (Gujarat and Porter, 2009). The results of the ADF and PP tests are summarized in Table 5.2. As we expected, the prices across the nine markets are non-stationary. The null hypothesis test of the series cannot be rejected for all the nine markets. After taking the first difference of all the series, the null hypothesis is rejected at $1 \%$ significant level. The PP test concurs with the ADF test. The price series for the nine markets are $I(1)$ i.e. first difference stationary.

Table 5.2: Results of ADF and PP unit root tests on real monthly prices

\begin{tabular}{l|cc|cc}
\hline \multirow{2}{*}{ Markets } & \multicolumn{2}{|c|}{ ADF test } & \multicolumn{2}{c}{ PP test } \\
\cline { 2 - 5 } & level & first diff & level & first diff \\
\hline Eldoret & -1.169 & $-12.498 * * *$ & -1.176 & $-12.399 * * *$ \\
Garissa & -0.857 & $-13.880 * * *$ & -0.758 & $-14.130 * * *$ \\
Kisumu & -1.024 & $-11.120 * * *$ & -1.003 & $-10.809 * * *$ \\
Kisii & -0.248 & $-13.174 * * *$ & -0.856 & $-13.108 * * *$ \\
Kitale & -0.248 & $-7.611 * * *$ & 0.070 & $-7.350 * * *$ \\
Machakos & -0.074 & $-13.228 * * *$ & -0.899 & $-13.020 * * *$ \\
Mombasa & -1.282 & $-13.153 * * *$ & -1.285 & $-13.229 * * *$ \\
Nairobi & -1.214 & $-12.834 * * *$ & -1.217 & $-12.809 * * *$ \\
Nakuru & -1.212 & $-11.560 * * *$ & -1.238 & $-11.322 * * *$ \\
\hline Asterisk *** and $* *$ signifies rejection of the null hypothesis of a unit root at $1 \%$ and $5 \%$ significant level \\
respectively
\end{tabular}

We test for pairwise cointegration between the surplus and deficit markets using Johansen's maximum likelihood vector auto-regression approach (Johansen and Juselius, 1990). To evaluate the policy effects on market integration the data is split into two sample representing two policy regimes as discussed earlier. Regime one covers the period of a fully liberalized maize sector. There was little or no policy intervention from the government with market forces guiding the sector. The second regime was the period after high food crises and government implementing various policies to stabilize food prices. The policies implemented to mitigate against high food prices included, the fertilizer subsidy, zero rating of import duty on maize, NCPB participation in the market and import ban on GMO foodstuff.

Cointegration tests was done on the full sample and for each policy regime. Results for the full sample and each regime are summarized in Table 5.3.

From the full sample, results indicate not all the surplus and deficit markets are cointegrated. Eldoret is cointegrated to five markets while Kitale is cointegrated to four. Market pairs that were further apart were not cointegrated. For example, Garissa market is not cointegrated with both surplus markets. The market is over 700 kilometres away. When we consider the two 
policy regimes, the results differs. Under regime one all the surplus markets are cointegrated with their respective deficit markets. This is not the case under regime two. Only two pairwise markets (Nairobi and Mombasa) are cointegrated with both surplus markets. The lack of market integration under regime two may be attributed to the various policies implemented to mitigate against high food prices that distorts the markets. Nairobi is the capital city and Mombasa is the second biggest city after Nairobi. Mombasa it also the entry point of maize coming from overseas as the port is located in the town. The two cities have well-developed infrastructure and are linked to the surplus markets. This may explain why the two markets were cointegrated under regime two.

Table 5.3: Johansen's cointegration test statistics for surplus and deficit markets

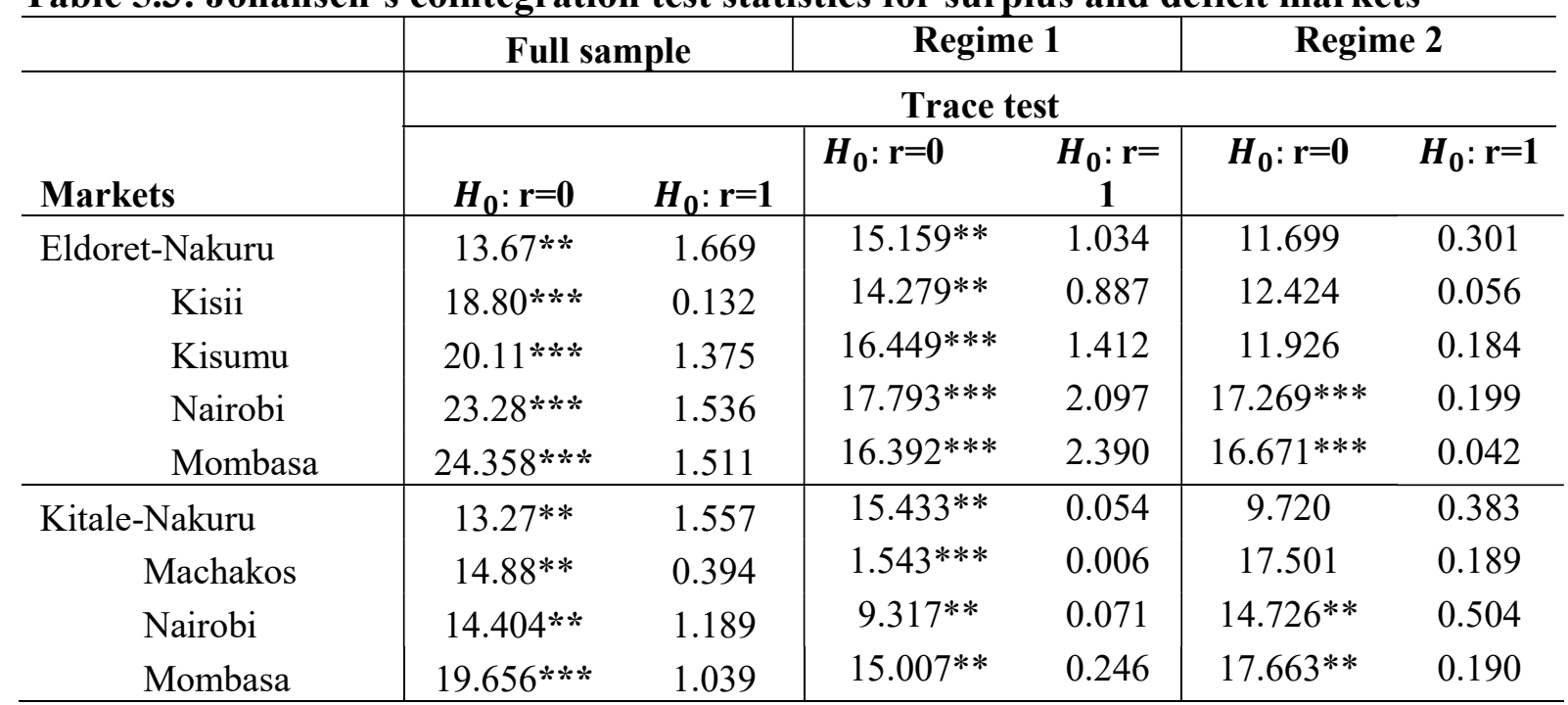

Asterisk *** and $* *$ signifies rejection of the null hypothesis of no cointegration vector at $1 \%$ and $5 \%$ significant level respectively. Regime 1 (Jan-2000-Dec-2007) following liberalization of the sector when there was minimal or no policy intervention by the government. Market forces determined maize prices. Regime 2(Jan-2008-Dec2016) following food price hikes and government implementation of policies aimed at stabilizing food prices e.g. fertilizer subsidy, NCPB participation in the market etc. $H_{0} r=0$ represent null hypothesis no cointegration $H_{0} r=1$ represents null hypothesis at most 1 cointegrating value.

We estimate two TAR models: The standard-TAR model (3.7) that assumes a constant transaction cost and the extended-TAR model (3.8) that relaxes this assumption in the threshold and adjustment parameters. These two models examine price responses in the surplus market as a result of shock in the deficit markets. The standard-TAR model results are summarized in Table 5.4.

Markets that were further apart had a higher transaction costs $\left(\tau^{d s}\right)$ compared to markets nearer each other. Overall, the mean transaction costs between the surplus and deficit market was 0.25 . Eldoret and it respective pairwise markets had a lower transaction costs of 0.16 compared to Kitale and its respective pairwise markets of 0.31 . If the price difference between the surplus and deficit market pairs was higher than transaction costs. To achieve equilibrium between the two markets, the price 
difference was corrected by a mean speed of adjustment of -0.42 with a half-life of 1.5 months. Halflife captures the time taken for a shock to return to half its initial value. In our case, the shock is the price difference between surplus and deficit markets higher than transaction costs. Eldoret and its respective pairwise markets had a higher speed of adjustment (-0.52) and lower half-life (1.1 months) compared to Kitale and its respective pairwise market with a speed of adjustment of (-0.34) and halflife (1.7 months). Markets closer to each other have a higher speed of adjustment, lower half-life and low transaction costs compared to pairwise markets far from each other. The Eldoret and Nakuru market pair is a good example compared to the other markets.

Table 5.4: TAR results on adjustment parameter, threshold and half-life

\begin{tabular}{c|cccc}
\hline Market pairs & Dist. & $\boldsymbol{\tau}^{\boldsymbol{d s}}$ & $\boldsymbol{\rho}^{\text {out }}$ & $\lambda^{s}$ \\
\hline Eldoret-Nakuru & 156 & 0.14 & $\begin{array}{c}-0.733^{* * *} \\
(-10.99)\end{array}$ & 0.5 \\
Kisii & 195 & 0.17 & $\begin{array}{c}-0.760^{* * *} \\
(-10.47)\end{array}$ & 0.5 \\
Kisumu & 118 & 0.21 & $\begin{array}{c}-0.364^{* * *} \\
(--6.143)\end{array}$ & 1.5 \\
Nairobi & 311 & 0.17 & $\begin{array}{c}-0.400^{* * *} \\
(-7.110)\end{array}$ & 1.4 \\
Mombasa & 796 & 0.11 & $\begin{array}{c}-0.345^{* * *} \\
(-4.809)\end{array}$ & 1.6 \\
\hline Kitale-Nakuru & 227 & 0.13 & $\begin{array}{c}-0.247^{* * *} \\
(-3.672)\end{array}$ & 2.4 \\
Kisii & 265 & 0.15 & $\begin{array}{c}-0.284^{* * *} \\
(-3.209)\end{array}$ & 2.1 \\
Kisumu & 158 & 0.39 & $\begin{array}{c}-0.480^{* * *} \\
(-7.643)\end{array}$ & 1.1 \\
Machakos & 447 & 0.12 & $\begin{array}{c}-0.366^{* * *} \\
(-3.471)\end{array}$ & 1.5 \\
Garissa & 711 & 0.85 & $\begin{array}{c}-0.480^{* * *} \\
(-7.643)\end{array}$ & 1.1 \\
Nairobi & 382 & 0.30 & $\begin{array}{c}-0.348 * * * \\
(-6.876)\end{array}$ & 1.6 \\
Mombasa & 867 & 0.22 & $\begin{array}{c}-0.233^{* * *} \\
(-3.725)\end{array}$ & 2.6 \\
\hline
\end{tabular}

The asterisks $*$ and $* *$ denote significance of the adjustment parameters at the $5 \%$ and $1 \%$ levels respectively, with the t-values of the speeds of price adjustment given in the brackets (it's the estimated adjustment speed in the outer regimes). The half-lives of price adjustment for the producer and consumer markets respectively, are measured in months and computed as $\lambda^{s}=\ln (0.5) / \ln (\rho)$. Dist. is the distance in kilometres between surplus and deficit markets. $\tau^{d s}$ represents transaction costs between pairwise markets. $\rho^{\text {out }}$ is the speed of adjustment when price margin surpasses the transaction costs. $\lambda^{s}$ is the half-life which represent the time taken for the shock to return to half of its initial value.

The Extended-TAR model includes a time trend to counter the standard literature assumption of constant transaction costs (Goodwin and Piggot, 2001; Sarno et al. 2004). When we have non-standard transfer costs, it yields better results as it represents the true scenario in the field, compared to the standard-TAR. Results for our extended-TAR are summarized in Table 5.5. 
As we expected, there was an increase with respect to the speed of adjustment and reduction in the half-life. Using the constant transaction costs under-estimates the threshold parameters. Similar to results in the standard-TAR markets that were further apart had a higher transaction $\operatorname{costs}\left(\tau^{d s}\right)$ compared to markets nearer each other. Overall, the mean transaction costs between surplus and deficit market was 0.24. Eldoret and it respective pairwise markets had a lower transaction costs of 0.17 compared to Kitale and its respective pairwise markets of 0.30 . If the price difference between the surplus and deficit market pairs was higher than transaction costs. To achieve equilibrium between the two markets, the difference was corrected by a mean speed of adjustment of -0.50 with a half-life of 1.3 months. Eldoret and its respective pairwise markets had a higher speed of adjustment (-0.61) and lower half-life (0.95 months) compared to Kitale and its respective pairwise market with a speed of adjustment of (-0.40) and half-life (1.7 months). Markets closer to each other have a higher speed of adjustment, lower half-life and low transaction costs compared to pairwise markets far from each other. The Eldoret and Nakuru market pair is a good example compared to the other markets. Eldoret town is third in milling capacity in the country. Major large and medium scale traders are located within Eldoret and these traders have satellite premises in the deficit region. The town is a major assembly point of maize coming from surplus region and Uganda. In addition, the high speed of adjustment may be attributed use of high-speed information and communication system, such as the use of the mobile phone and market information platforms. This may explain the results in both the standard-TAR and extended-TAR. Models. 
Table 5.5: Extended-TAR results on adjustment parameter, threshold and half-life

\begin{tabular}{|c|c|c|c|c|c|}
\hline Market pairs & Dist. & $\tau^{d s}$ & $\rho^{\text {out }}$ & $\rho^{\prime}$ & $\lambda^{s}$ \\
\hline Eldoret-Nakuru & 156 & 0.13 & $\begin{array}{c}-0.903 * * * \\
(-6.198)\end{array}$ & $\begin{array}{l}0.0016 \\
(1.241)\end{array}$ & 0.3 \\
\hline Kisii & 195 & 0.17 & $\begin{array}{c}-0.869 * * * \\
(-6.843)\end{array}$ & $\begin{array}{c}0.001271 \\
(1.0456)\end{array}$ & 0.3 \\
\hline Kisumu & 118 & 0.21 & $\begin{array}{c}-0.293 * * \\
(-2.547)\end{array}$ & $\begin{array}{c}-0.000595 \\
(0.7947)\end{array}$ & 2.0 \\
\hline Machakos & 376 & 0.23 & $\begin{array}{c}-0.740 * * * \\
(-6.091)\end{array}$ & $\begin{array}{c}0.001033 \\
(0.875)\end{array}$ & 0.5 \\
\hline Nairobi & 311 & 0.2 & $\begin{array}{c}-0.435 * * * \\
(-5.192)\end{array}$ & $\begin{array}{c}0.000918 \\
(1.0195)\end{array}$ & 1.2 \\
\hline Mombasa & 796 & 0.1 & $\begin{array}{c}-0.396 * * * \\
(-3.82)\end{array}$ & $\begin{array}{c}0.000723 \\
(0.706)\end{array}$ & 1.4 \\
\hline Kitale-Nakuru & 227 & 0.11 & $\begin{array}{c}-0.277 * * * \\
(-3.092)\end{array}$ & $\begin{array}{c}-0.00032 \\
(-0.401)\end{array}$ & 2.1 \\
\hline Kisii & 265 & 0.27 & $\begin{array}{c}-0.309 * * \\
(-2.349)\end{array}$ & $\begin{array}{c}0.005798 \\
(1.905)\end{array}$ & 1.9 \\
\hline Kisumu & 158 & 0.28 & $\begin{array}{c}-0.543 * * * \\
(-5.80)\end{array}$ & $\begin{array}{c}0.000139 \\
(0.279)\end{array}$ & 0.9 \\
\hline Machakos & 447 & 0.12 & $\begin{array}{c}-0.841 * * * \\
(-4.728)\end{array}$ & $\begin{array}{c}0.002689^{* *} \\
(2.143)\end{array}$ & 0.4 \\
\hline Garissa & 711 & 0.85 & $\begin{array}{c}-0.260 * * * \\
(-3.285)\end{array}$ & $\begin{array}{c}0.003371^{* *} \\
(2.128)\end{array}$ & 2.3 \\
\hline Nairobi & 382 & 0.28 & $\begin{array}{c}-0.322 * * * \\
(-5.488)\end{array}$ & $\begin{array}{c}-0.000556 \\
(-1.066)\end{array}$ & 1.8 \\
\hline Mombasa & 867 & 0.22 & $\begin{array}{c}-0.253 * * * \\
(-3.176)\end{array}$ & $\begin{array}{c}-0.00094 \\
(0.126)\end{array}$ & 2.4 \\
\hline
\end{tabular}

The asterisks * and ** denote significance of the adjustment parameters at the $5 \%$ and $1 \%$ levels respectively, with the t-values of the speeds of price adjustment given in the brackets (it's the estimated adjustment speed in the outer regimes). The half-lives of price adjustment for the producer and consumer markets respectively, are measured in months and computed as $\lambda^{s}=\ln (0.5) / \ln (\rho)$. Dist. is the distance in kilometres between surplus and deficit markets. $\tau^{d s}$ represents transaction costs between pairwise markets. $\rho^{\text {out }}$ is the speed of adjustment when price margin surpasses the transaction costs. $\rho^{\prime}$ is the time trend. $\lambda^{s}$ is the half-life which represent the time taken before the shock can reduce to half of its original value.

To evaluate the effects of policy on market integration. We split the data into two samples to correspond to two policy regimes. Regime one (Jan-2000-Dec-2007) is the era corresponding to full liberalization of the maize sector. The regime was characterized by minimal or no policy intervention from the government. Market forces determined maize prices. There was an increase in the private sector players along the value chain that promoted competition. Regime two (Jan-2008-Dec-2016) follows the world high food crises and subsequent domestic food price hikes. It was characterised by government participation into the market to stabilize food prices. Several policies were implemented with the aim of stabilizing food prices. Policies implemented included, the fertilizer subsidy, zero rating of import duty on maize, NCPB participation in the market and import ban on GMO foodstuff. 
The results of the extended-TAR models under the two regimes are summarized in Table 5.6. Under regime one, markets that were further apart had a higher transaction $\operatorname{costs}\left(\tau^{d s}\right)$ compared to markets nearer each other. Overall, the mean transaction costs between the surplus and deficit market was 0.28 . Eldoret and it respective pairwise markets had a lower transaction cost of 0.26 compared to Kitale and its respective pairwise markets of 0.30 . If the price difference between the surplus and deficit market pairs was higher than transaction costs. To achieve equilibrium between the two markets, the difference was corrected by a mean speed of adjustment of -0.53 with a half-life of 1.6 months. Eldoret and its respective pairwise markets had a higher speed of adjustment of -0.63 and lower half-life of 0.96 months compared to Kitale and its respective pairwise market with a speed of adjustment of -0.42 and half-life of 2.5 months. Under regime two the introduction of policies to stabilize prices under this regime resulted in market distortion as the price difference between surplus and deficit markets were not corrected hence no equilibrium was achieved. The two markets were not integrated under this regime except for Nakuru and Mombasa markets. 
Table 5.6: Extended-TAR results on adjustment parameter, threshold and half life under the two policy regimes

\begin{tabular}{|c|c|c|c|c|c|c|c|c|}
\hline \multirow[t]{2}{*}{ Market pairs } & \multicolumn{4}{|c|}{$\begin{array}{l}\text { Regime 1-Minimal or no policy interventions - } \\
\text { liberalized maize sector (Jan 2000-Dec-2007) }\end{array}$} & \multicolumn{4}{|c|}{$\begin{array}{l}\text { Regime 2-Following high food crises- discretionary } \\
\text { policy interventions (Jan-2008-Dec-2016) }\end{array}$} \\
\hline & $\tau^{d s}$ & $\rho^{\text {out }}$ & $\rho^{\prime}$ & $\lambda^{s}$ & $\tau^{d s}$ & $\rho^{o u t}$ & $\rho^{\prime}$ & $\lambda^{s}$ \\
\hline Eldoret-Nakuru & 0.13 & $\begin{array}{c}-0.881 * * * \\
(-4.67)\end{array}$ & $\begin{array}{l}-0.002 \\
(-0.56)\end{array}$ & 0.3 & 0.12 & $\begin{array}{c}-0.648^{* * *} \\
(-4.39)\end{array}$ & $\begin{array}{l}-0.000 \\
(-0.10)\end{array}$ & 0.7 \\
\hline Kisii & 0.30 & $\begin{array}{c}-0.848 * * * \\
(-3.26)\end{array}$ & $\begin{array}{l}0.008 \\
(1.32)\end{array}$ & 0.4 & 0.28 & $\begin{array}{c}0.044 \\
(0.144)\end{array}$ & $\begin{array}{l}-0.001 \\
(-0.27)\end{array}$ & 16.1 \\
\hline Kisumu & 0.27 & $\begin{array}{c}-0.448^{* * *} \\
(-6.14)\end{array}$ & $\begin{array}{c}0.013 * * * \\
(5.59)\end{array}$ & 1.2 & 0.24 & $\begin{array}{l}-0.068 \\
(-0.62)\end{array}$ & $\begin{array}{l}-0.001 \\
(-0.72)\end{array}$ & 9.8 \\
\hline Nairobi & 0.36 & $\begin{array}{c}-0.672 * * * \\
(-5.26)\end{array}$ & $\begin{array}{c}0.021 * * * \\
(4.65)\end{array}$ & 0.6 & 0.17 & $\begin{array}{l}-0.187 \\
(-1.58)\end{array}$ & $\begin{array}{l}0.001 \\
(0.27)\end{array}$ & 3.3 \\
\hline Mombasa & 0.26 & $\begin{array}{c}-0.264 * * * \\
(-3.38)\end{array}$ & $\begin{array}{c}0.009 * * * \\
(3.68)\end{array}$ & 2.3 & 0.08 & $\begin{array}{l}-0.269 \\
(-1.65)\end{array}$ & $\begin{array}{l}0.002 \\
(0.85)\end{array}$ & 2.3 \\
\hline Kitale-Kisumu & 0.20 & $\begin{array}{c}-0.254 * * * \\
(-3.27)\end{array}$ & $\begin{array}{l}-0.020 \\
(-1.74)\end{array}$ & 3.1 & 0.44 & $\begin{array}{c}-0.557 \\
(-1.230)\end{array}$ & $\begin{array}{l}0.002 \\
(1.21)\end{array}$ & 0.2 \\
\hline Garissa & 0.44 & $\begin{array}{c}-0.987 * * \\
(-2.45)\end{array}$ & $\begin{array}{l}0.015 \\
(0.94)\end{array}$ & 0.1 & 0.54 & $\begin{array}{l}-0.600 \\
(-1.37)\end{array}$ & $\begin{array}{l}0.002 \\
(0.72)\end{array}$ & 0.8 \\
\hline Nairobi & 0.22 & $\begin{array}{c}-0.145^{* * *} \\
(-0.76)\end{array}$ & $\begin{array}{l}-0.007 \\
(-1.10)\end{array}$ & 4.4 & 0.21 & $\begin{array}{c}-0.529 \\
(-1.200)\end{array}$ & $\begin{array}{l}0.003 \\
(1.64)\end{array}$ & 0.4 \\
\hline Mombasa & 0.32 & $\begin{array}{c}-0.273 * * \\
(-2.34)\end{array}$ & $\begin{array}{l}0.003 \\
(0.39)\end{array}$ & 2.2 & 0.25 & $\begin{array}{c}-0.993 * * \\
(-2.07)\end{array}$ & $\begin{array}{l}0.005 \\
(1.82)\end{array}$ & 0.1 \\
\hline
\end{tabular}

The asterisks * and ** denote significance of the adjustment parameters at the $5 \%$ and $1 \%$ levels respectively, with the t-values of the speeds of price adjustment given in the brackets (it's the estimated adjustment speed in the outer regimes). The half-lives of price adjustment for the producer and consumer markets respectively, are measured in months and computed as $\lambda^{s}=\ln (0.5) / \ln (\rho) . \tau^{d s}$ represents transaction costs between pairwise markets. $\rho^{\text {out }}$ is the speed of adjustment when price margin surpasses the transaction costs. $\rho^{\prime}$ is the time trend. $\lambda^{s}$ is the half-life which represent the time taken before the shock can reduce to half of its original value. Policies implemented under regime two included, fertilizer subsidy, zero rating of import duty on maize, NCPB participation in the market and import ban on GMO foodstuff. 


\subsection{Conclusion and policy recommendations}

Well-integrated market systems connected by fast and efficient arbitrage allows for efficient movement of trade flow and the exchange of food products across surplus and deficit regions. Well-integrated markets have impact on price discovery and market operations and are significant in addressing high and volatile food prices. When markets are not properly integrated price mechanism does not work and price signals cannot be transmitted thus allowing for the efficient exchange of food products across spatial markets. The aim of the study was to examine spatial market integration and the effects of policy in the era of high food prices. Market pairs close to each other were integrated, had a lower transaction costs and the price differential across the surplus and deficit markets were quickly corrected compared to markets further apart. Policy implemented to stabilize food prices did not achieve their desired effects and resulted in market distortion.

To reduce transaction costs the government should improve the road infrastructure connecting production areas and the markets. There is need to harmonize local government levies imposed on maize traversing different local municipalities to avoid multiple taxation.

Given the effects policies have on spatial market integration, it is important for the government to implement policies appropriately to achieve their desired effects. Proper consultation and coordination among government institutions involved in the policy implementation will facilitate optimal policy output. On the fertilizer subsidy, the government needs to collaborate with the private sector as it has a wide distribution network countrywide. This will ensure accessibility of fertilizer by small-scale farmers in remote areas. Market forces should guide market participation by NCPB. The board should not succumb to political pressure to purchasing maize at a higher price than the prevailing prices. To ensure consumers benefit from cheap imported maize during drought periods, the government should consider reviewing the ban on GMO foodstuffs. 


\section{References}

Abate, T., Mugo, S., De Groote, H. and Regassa, M.W. 2015. DT maize, quarterly bulletin of the Drought Tolerant Maize for Africa project Vol 4. No. 3 September 2015.

Amikuzuno, J. 2010. Spatial price transmission and market integration between fresh tomato markets in Ghana: Any benefits from trade liberalisation. Department of Agricultural Economics and Extension, University for Development Studies, Tamale, Ghana

Baltzer, K. 2013. International to domestic price transmission in fourteen developing countries during the 2007-08 food crisis. WIDER Working Paper No. 2013/031 Helsinki: UNU-WIDER.

Barret, C.B. 1996.Market analysis methods: Are our enriched toolkits well suited to enliven the markets? American Journal of Agricultural Economics, 78 (3): 825-829.

Barrett, C.B. 2001. Measuring integration and efficiency in international agricultural markets. Review of Agricultural Economics, 23:19-32.

Barrett, C.B. and Li, J. R. 2002. Distinguishing between equilibrium and integration in spatial price analysis. American Journal of Agricultural Economics, 84(2), 292-307.

Baulch, B. 1997. Testing for food market integration revisited. Journal of Development Studies, 33:512-34.

Bellemare, M. F., Barret, C. B. and Just, D. R. 2013. The welfare impacts of commodity price volatility: Evidence from rural Ethiopia.

Benson, T., Mugarura, S. and Wanda, K. 2008. Impact in Uganda of rising global food prices: The role of diversified staples and limited price transmission. Agricultural Economics, 39:513-24.

Bryan, S. 2015. A cacophony of policy responses: evidence from 14 Countries during the 2007-08 Food Crisis. In P. Pinstrup-Andersen (ed.), Food Price Policy in an Era of Market Instability: A Political Economy Analysis. Oxford: Oxford University Press.

Chan, K.S. 1993. Consistency and the limiting distribution of the least squares estimator of a threshold autoregressive model. The Annals of Statistics, 21:520-533.

Chan, N. H., Yau, C.Y. and Zang, R.M. 2015. LASSO estimation of threshold autoregressive models. Journal of Econometrics, 189:285-296.

Chapoto, A. and Jayne, T.S. 2009. The Impact of trade barriers and market interventions on maize price predictability evidence from Eastern and Southern Africa. Michigan State University International Development Draft Working Paper No. 102 .Department of Agricultural Economics. East Lansing, MI: Michigan State University. 
Chapoto, A and Sitiko, N. 2014. Understanding the effects of trade restriction on maize prices. Presentation to COMESA/ACTESA Parliamentary Policy Seminar on Import and Export Ban Lusaka 11-12 August 2014.

Cudjoe, G., Breisinger, C. and Diao, X. 2010. Local impact of a global crisis: Food price transmission, consumer welfare and poverty in Ghana. Food Policy, 35(4): 294-302.

Enke, S. 1951. Equilibrium among spatially separated markets: Solution by electrical analogue. Econometrica, 19: 40-47.

Finkelshtain, I. and Chalfant, J. 1991. Marketed surplus under risk: Do peasants agree with Sandmo? American Journal of Agricultural Economics 73: 557-567.

Gbegbelegbe, S. and De Groote, H. 2012. Spatial and temporal maize price analysis in East Africa. Poster paper presentation at the International Association of Agricultural Economists (IAAE) Triennial Conference, 18-24 August 2012, Foz do Iguaçu, Brazil.

Goodwin, B.K. and Piggott, N.E. 2001. Spatial market integration in the presence of threshold effects. Journal of Agricultural Economics, 83 (2): 302-317.

Gujarati, D.N. and Porter, D. C. 2009.Basic econometrics. International edition. McGraw-Hill Education,2 Penn Plaza, New York. NY 10121.

Jayne, T.S., Yamano, T., Nyoro, J. and Awour, T. 2001. Do farmers really benefit from high food prices? Balancing rural interests in Kenya's maize pricing and marketing policy. Working Paper No. 2b, Tegemeo Institute. Egerton University. Nairobi, Kenya.

Hansen, B.E. 1996. Inferences in TAR models. Boston College working paper 325, Department of Economics Boston College.

Jayne, T.S. 2012. Managing food price instability in East and Southern Africa. Global Food Security, $1(2), 143-149$.

Johansen, S. and Juselius, K. 1990. Maximum likelihood estimation and inference on cointegration with applications to the demand for money. Oxford Bulletin of Economics and Statistics, 52(2):169-210.

Johansen, S. 1991. Estimation and hypothesis testing of cointegration vectors in Gaussian vector autoregressive models. Econometrica, Vol. 59 (6): 1551-1580.

Kamau, M., Olwande, J. and Githuku, J. 2011. Consumption and expenditures on key food commodities in urban households: The case of Nairobi. Tegemeo Working Paper No. 40. Tegemeo Institute. Egerton University. Nairobi, Kenya.

Karugia, J., Wanjiku, J., Michael, W. and Suresh, B. 2010. Persistence of high food prices in Eastern Africa: What role for policy? ReSAKSS, ILRI, Nairobi, 2010.

Kenya Road Board. 2015. Annual reports and financial statements 2014/2015. 
Kirimi, L., Sitko, N.,Jayne, T.S., Karin, F., Muyanga, M., Sheahan, M., Flock, J. and Bor, G. 2011. A farm gate-to-consumer value chain analysis of Kenya maize marketing system. Working Paper no.44. Tegemeo Institute. Egerton University. Nairobi, Kenya.

Li, D. and Ling, S. 2012. On the least squares estimation of multiple-regime threshold autoregressive models. Journal of Econometrics 167: 240-253.

McNew, K. and Fackler, P.L.1997. Testing market equilibrium: Is cointegration informative? Journal of Agricultural and Resource Economics, 22(2), 191-207.

Minot, N. 2011. Transmission of world food price changes to markets in Sub-Saharan Africa. International Food Policy Research Institute Discussion Paper Series, 01059 (January), 1-44.

Minot, N. 2014. Food price volatility in Sub-Saharan Africa: Has it really increased? Food Policy, 45 : $45-56$.

Negassa, A. and Myers, R. 2007. Estimating policy effects on spatial market efficiency: An extension to the parity bounds model. American Journal of Agricultural Economics, 89(2), 338-352.

Ngare, L. W., Wambugu, S.K., Nzuma, J.M. and Shisanya, C. 2013. Asymmetric price transmission in food markets in the highlands of Central Kenya. Invited paper presented at the 4th International Conference of the African Association of Agricultural Economists, September 22-25, 2013, Hammamet, Tunisia.

Njagi, T., Wanyama, R. and Mbaka, S.M. 2015. Tegemeo agriculture policy research analysis (TAPRA) II project.2014 rural household survey report. Tegemeo Institute. Egerton University. Nairobi, Kenya.

Nzuma, J.M. 2013. The political economy of food price policy: Kenya country case'. WIDER Working Paper 2013/026. Helsinki: UNU-WIDER.

Nzuma, J.M., Karugia, T. J., Wanjiku, J., Wambua, J. and Kirui, O. 2013. Staple food price volatility and its policy implications in Kenya. Contributed paper prepared for submission to the 4th Conference of the African Association of Agricultural Economists (AAAE), 22-25 September 2013, Tunisia.

Opiyo J., Kirimi, L., Kinyumu, N., and Makau, J. 2015. Cost of maize production under different systems in Kenya: The role of policy interventions. Policy Brief No.18. Tegemeo Institute. Egerton University. Nairobi, Kenya.

Organisation for Economic Coordination and Development (OECD), Food, and Agriculture Organisation of the United Nations (FAO). 2016. OECD-FAO Agricultural outlook 20162025 .

Samuelson, P.A. 1952. Spatial price equilibrium and linear programming. American Economic Review, 42:283-303. 
Sarno, L., Taylor, M. P. and Chowdhury, I. 2004. Nonlinear dynamics in deviation from the law of one price: A broad-based empirical study. Journal of International Money and finance, 23:125.

Suri, T., Tschirely, D., Irungu, C., Gitau, R. and Kariuki, D. 2008. Rural income, inequality and poverty dynamics in Kenya. Tegemeo Working Paper No. 30, Tegemeo Institute. Egerton University. Nairobi, Kenya.

Takayama, T. and. Judge, G.A. 1971. Spatial and temporal price and allocation models. Amsterdam: North-Holland.

Tong, H. and Lim, K. S. 1980. Threshold auto regression, limit cycles, and cyclical data (with discussions). Journal of the Royal Statistical Society. Series B, 42:245-292.

Tong, H. 1990. Non-linear time series. A dynamic system approach, Oxford. Oxford University Press.

Turnovsky, S.J., Shalit, H. and Schmitz, A. 1980. Consumer's surplus, price instability, and consumer welfare." Econometrica 48: 135-152.

Van Campenhout, B. 2007.Modelling trends in food market integration: Method and an application to Tanzanian maize markets. Food Policy, 32: 112-127.

World Bank. 2009. Eastern Africa: A study of the regional maize market and marketing costs. Agriculture and Rural Development Unit. Sustainable Development Department. African Region (unpublished). 